\title{
Housing Discrimination and Health: Understanding Potential Linking Pathways Using a Mixed-Methods Approach
}

\author{
Roshanak Mehdipanah ${ }^{1, *}$, Jessica Ramirez ${ }^{1}$, Shanti Abedin ${ }^{2}$ and Sherrill F. Brown ${ }^{2}$ \\ 1 Department of Health Behavior and Health Education, School of Public Health, University of Michigan, \\ Ann Arbor, MI 48109-2029, USA; jesramir@umich.edu \\ 2 National Fair Housing Alliance, Washington, DC 200004, USA; Sabedin@nationalfairhousing.org (S.A.); \\ Sbrown@nationalfairhousing.org (S.F.B.) \\ * Correspondence: rmehdipa@umich.edu; Tel.: +1-734-763-1788
}

Received: 15 September 2018; Accepted: 9 October 2018; Published: 12 October 2018

check for

\begin{abstract}
Few studies have examined the impact of housing discrimination on health. This study explores potential pathways linking housing discrimination and health using concept mapping, a mixed-method approach. Participants included employees from twenty Fair Housing Organizations nationwide who participated in two online sessions, brainstorming, and structuring. Responses were generated representing biological, social, economic, and physical connections between housing discrimination and health. Using hierarchical cluster analysis, five clusters were identified: (1) Access and barriers; (2) Opportunities for growth; (3) Neighborhood and communities; (4) Physical effects of housing discrimination; and (5) Mental health. Clusters 1 (4.09) and 2 (4.08) were rated as most important for health, while clusters 2 (3.93) and 3 (3.90) were rated as most frequently occurring. These findings add to the limited evidence connecting housing discrimination to health and highlight the need for studies focusing on the long-term health effects of housing discrimination on individuals and neighborhoods.
\end{abstract}

Keywords: housing; discrimination; health inequity; urban health; concept mapping

\section{Background}

\subsection{Housing Discrimination}

The federal Fair Housing Act of 1968, prohibits discrimination in housing based on race, color, religion, sex, national origin, familial status, and disability, related to the purchase, rental, leasing, sale, or financing of a residence, so as to contribute to segregated housing patterns or to prevent neighborhood, community, or development choice (Calmore 1997; US Department of Justice 2017). Many state or local laws also prohibit discrimination based on marital status, sexual orientation, source of income, military discharge status, age, and other locally-protected classes (Calmore 1997). However, although blatant acts of housing discrimination are less common now than they were when the Act was passed 50 years ago, housing discrimination continues to be an issue, and it often goes unreported or undetected (Turner et al. 2016). In 2017, there were 28,843 reported complaints of housing discrimination across the U.S., a 2.3\% increase compared to the previous year. Of these cases, $56.7 \%$ were based on having a disability and $18.5 \%$ on the basis of race (National Fair Housing Alliance 2018). However, a recent surge in hate crimes, harassment, and activity have resulted in approximately $27.3 \%$ of these cases occurring near or in a place of residency with activities that can intimidate, threaten, coerce, or injure an individual's ability to enjoy their home because of their race, color, ethnicity, gender, disability, religion, or family status (National Fair Housing Alliance 2018). 


\subsection{Housing Discrimination and Health}

Few studies have directly examined the impact of housing discrimination on health and health inequities, or the specific pathways through which effects on health occur. A recent study in Philadelphia found a significant negative association between perceived housing discrimination and self-reported health among individuals living in neighborhoods with higher housing values (Yang et al. 2016). Another study in Southeastern Wisconsin found that black women experienced reduced colorectal cancer survival rates in neighborhoods that had higher racial bias in the mortgage lending process (Zhou et al. 2017). While such studies remain sparse, there are other studies that have linked housing discrimination to barriers in education, employment, and economic growth (Bell et al. 2006), all important correlates of health and well-being. Furthermore, some of the research has focused on the negative neighborhood consequences of race-based housing discrimination, contributing to residential segregation and restricting people of color to less desirable areas (Roscigno et al. 2009; Williams and Jackson 2005). In a recent study using the 2012 Housing Discrimination Study, which consists of data from audits conducted to investigate cases, the authors provided strong evidence of illegal steering by real estate agents that constrained the choices for housing in low-resourced neighborhoods for non-White buyers (Christensen and Timmins 2018). Such studies focusing on neighborhood effects along with empirical research linking housing discrimination directly to health outcomes are suggestive of the public health implications of continuing housing discrimination. However, more evidence is needed to better understand these underlying mechanisms.

Furthermore, as urban populations increase, cities like Chicago, Los Angeles, and New York are experiencing an increase in housing values and a shortage of affordable housing, resulting in the gentrification of neighborhoods largely occupied by people of color, seniors, or populations of low-income (Chronopoulos 2016; Sims 2016; Betancur 2011). Housing discrimination can contribute to this process by reducing housing choices in these neighborhoods for populations already vulnerable to gentrification effects and can limit their relocation options to often under-resourced neighborhoods (National Fair Housing Alliance 2018; Betancur 2011). Research has proven the existence of racial residential segregation in U.S. metropolitan areas attributed to housing policies like the Federal Housing Administration of 1934 that determined where residents lived and whether they could access the benefits of homeownership based on the color of their skin (Massey and Denton 1993). Today, residential segregation continues to perpetuate health inequities, especially among Black and Latino communities that tend to reside in lower quality housing compared to their White counterparts, and have been limited in housing choice to neighborhoods where there is less access to healthy food and green space, and where there exists a higher likelihood of being exposed to hazardous waste sites (Erickson 2016) and contaminated water (Michigan Civil Rights Commission 2017). This is due to decades of disinvestment in these neighborhoods, created and reinforced both by discriminatory government policies and real estate industry behavior (Massey and Denton 1993; Acevedo-Garcia and Lochner 2003).

\subsection{Purpose}

The purpose of this study was to identify some of the potential pathways between housing discrimination and health. Through this exploratory approach, we will have a better understanding of the underlying mechanisms linking housing discrimination to health to further research and present solutions to address these issues.

\section{Methods}

\subsection{Study Design and Settings}

This study used concept mapping (CM), a mixed methods methodology that combines a qualitative approach with quantitative analysis to produce a conceptual map illustrating the perceptions of a group towards a specific situation (Kane and Trochim 2007). To increase our participant 
group, the study was completed online using Concept Systems Global Max ${ }^{\mathrm{TM}}$ software. The software allowed participants to connect remotely and anonymously to the project to complete the activities, while it permitted researchers to complete all the analyses.

\subsection{Participants}

Participants for this study were employees working at Fair Housing Organizations across the top 20 most populous cities in the U.S. These are frontline professionals and see first-hand the effects of housing discrimination through daily interactions with individuals who have been affected. Purposive sampling techniques were used to recruit participants whose organizational contact information was obtained through the NHFA resource list. This group was identified as most of these larger cities have a long-time established and active Fair Housing Organization, compared to smaller cities. Identified participants were recruited via email and follow-up phone calls to ensure greater participation. Because of the flexibility of concept mapping and our inability to track participants due to anonymous participation, there was the possibility for participants who had not participated in the first online session (brainstorming) to still be invited to participate in the second session (structuring and rating).

\subsection{Data Collection and Analysis}

Concept mapping is conducted in six steps: preparation, generation, structuring, representation, interpretation, and utilization (Kane and Trochim 2007). Data collection occurs within the generation and structuring steps where participants brainstorm answers to the focus question, and then rate and sort these responses. More detailed explanations are provided for each of the steps elsewhere (Kane and Trochim 2007), however here we describe briefly the two data collection phases for each group. In addition to data collected through the concept mapping activities, participants were asked to complete a short questionnaire asking their age, gender, history of employment, location (state), and personal experience of housing discrimination in the past. Since data was collected anonymously, participants were asked to complete the participant questions for each session they participated in. All data was collected between March and July 2017 and was approved by the University of Michigan Institutional Review Board.

\subsubsection{Generation of Statements}

Participants were invited to join this first session via a link in the recruitment email. Consent was obtained through the online participation process, and once provided, participants were directed to the focus question: "One way housing discrimination affects people's well-being is ... " Definitions for the term well-being were provided as physical, emotional, or mental well-being. Since concept mapping is based on one question only, participants were invited to provide as many answers as they wished. At the end of the two week participation period, the research team reviewed all responses. Similar statements were edited or grouped to produce a final list for the structuring session.

\subsubsection{Structuring of Statements}

Participants were once again invited via a link in a follow-up email to participate in the structuring and rating of the statements. This session took place approximately six weeks from the first session to allow researchers to finalize the list of statements collected. First, participants were asked to sort the statements into groups or themes that made sense to them and to name each pile created. Second, participants were given a rating sheet with the same corresponding statements and asked to rate the prevalence and health importance of each statement on a 5-point Likert-type response scale. Prevalence referred to how prevalent or common each statement was based on the participants experience and included the categories (1) not prevalent, (2) somewhat prevalent, (3) prevalent, (4) very prevalent, and (5) extremely prevalent. Health importance referred to how important the effects of each of the statements had on health or wellbeing of individuals based on their experiences working in the field, 
and included the categories (1) little importance, (2) somewhat important, (3) important, (4) very important, and (5) extremely important.

\subsection{Data Analyses}

During the structuring session, data was entered directly into the online software and preliminary maps and rating lists were produced. The software uses groups' sorting data to create a similarity index which is used by the non-metric multidimensional scaling, a multivariate analysis, to map the points representing the distances and relations between the statements (Kane and Trochim 2007). From there, hierarchical cluster analysis was used to divide the map into clusters representing an idea or concept (Kane and Trochim 2007). A final cluster number was derived based on the different cluster's contents and themes. The rating information was used to determine each statement average mean importance rating and the proportion of subjects that considered a change as positive. Once cluster numbers were defined, average mean rankings and median rankings were calculated by cluster and used to create the cluster rating maps. These maps consisted of clusters with layers representing a value of the average importance rating (indicated in the legends of each map) for each group. Essentially, the more layers a cluster had the more important or prevalent it was perceived. Titles were derived from the descriptive label participants were asked to provide. The goodness of fit of the point map to the original similarity matrix was calculated using a diagnostic measure, the stress index, derived from multidimensional scaling. Therefore, a lower stress value indicates a better fit and a stronger relationship between the actual and optimal results (Kane and Trochim 2007).

\section{Results}

\subsection{Participant Characteristics}

A total of 17 people participated in the brainstorming session, and 14 people participated in the subsequent structuring session (Table 1). The average age of participants was 50 and 41 for the brainstorming and structuring sessions, respectively. For both sessions, most participants were female, and the majority had been working in the field of Fair Housing for more than 1 year, with the largest group having over 10 years of experience. Ten states were represented across both sessions, and most participants in both sessions expressed having had personal (individual or family) experiences with housing discrimination.

\subsection{Housing Discrimination and Health}

After the brainstorming session, a final list of 43 statements representing biological, social, economic, and physical connections were generated. Supplementary 1 presents all 43 statements generated by the participants, separated into clusters representing different themes and their ratings based on importance for health and prevalence of occurrence. For concept mapping projects, the average stress values range from 0.205 and 0.365 indicating how accurate the point maps were in indicating the original values of the similarity matrix input (Kane and Trochim 2007). The stress index for this study was 0.22, placing it within the stated accepted range. In Figure 1, all statements grouped into five clusters are presented. Each point represents a statement (e.g., in cluster 2, Access and Barriers, the number 20 represents the statement, limits access to quality healthcare), while each layer represents either the average health importance rating (top map) or the prevalence rating (bottom map). The size of the cluster indicates the relationship between statements, where smaller clusters suggest a closer relation between statements within that cluster. The legend provides the rating values for each layer. 
Table 1. Characteristics of participants for the brainstorming and structuring sessions.

\begin{tabular}{ccc}
\hline & Brainstorming & Structuring \\
\cline { 2 - 3 } & $\mathbf{( N = 1 7 )}$ & $\mathbf{( N = 1 4 )}$ \\
\hline Average age & & \\
& 50.1 (Std. Dev. 13.7) & 41.4 (Std. Dev. 14.3) \\
\hline Gender & & \\
Female & $70.6 \%$ & $78.6 \%$ \\
Male & $17.7 \%$ & $21.4 \%$ \\
No response & $11.8 \%$ & 0 \\
\hline Years working in Fair Housing & \\
Less than 1 year & $5.9 \%$ & $14.3 \%$ \\
1-4 years & $11.8 \%$ & $21.4 \%$ \\
$5-9$ years & $29.4 \%$ & $28.6 \%$ \\
More than 10 years & $41.2 \%$ & $35.7 \%$ \\
No response & $11.8 \%$ & 0 \\
\hline State & & \\
NY & $5.9 \%$ & 0 \\
CA & 0 & $7.1 \%$ \\
IL & $5.9 \%$ & $7.1 \%$ \\
TX & $17.7 \%$ & $7.1 \%$ \\
PA & $5.9 \%$ & 0 \\
AZ & $5.9 \%$ & $7.1 \%$ \\
FL & 0 & $7.1 \%$ \\
MI & $11.8 \%$ & $42.9 \%$ \\
CO & $5.9 \%$ & $7.1 \%$ \\
DC & $11.8 \%$ & $14.2 \%$ \\
No response & $29.4 \%$ & 0 \\
\hline Personal experiences of housing discrimination & \\
Yes & $76.5 \%$ & 0 \\
No & $11.8 \%$ & \\
No response & $11.8 \%$ & \\
\hline & & \\
\hline
\end{tabular}

The analyses resulted in five cluster groups: access and barriers; opportunities for growth; neighborhood and communities; physical effects of housing discrimination; and mental health. Based on cluster averages, the statements in clusters (1) Access and barriers (4.09), and (2) Opportunities for growth (4.08), were rated as the most important for health, thus the multiple layers. When looking at prevalence of occurrence, cluster (2) Opportunities for growth (3.93), and cluster (3) Neighborhoods and communities (3.90), were the highest rated clusters. Clusters (3) Neighborhoods and communities, and (5) Mental health effects, had the most number of statements, twelve and eleven, respectively, while cluster (4) Physical effects of housing discrimination, had the least number of statements, six in total. While clusters (4) Physical effects, and (5) Mental effects, contained statements that described the immediate health impacts of housing discrimination, the cluster averages for both ratings were lower than the clusters that contained more long-term effects from housing discrimination both through economic and social opportunities found in cluster (2), Opportunities for growth.

When looking at statements independently of clusters, the statement prevents people from accumulating wealth (39) was perceived as the most important for health (4.46), while the statement segregation is perpetuated (43) was the most prevalent (4.54) by the group. Furthermore, the remaining top five most important for health statements: denies people access to various life opportunities (4.38), it restricts people's housing choice (4.31), prevent people from accumulating health (4.31), and limits housing options to an area with exposure to crime and violence (4.31), were also rated as the most prevalent statements, $4.31,4.31$. 4.23, and 4.15 , respectively. 


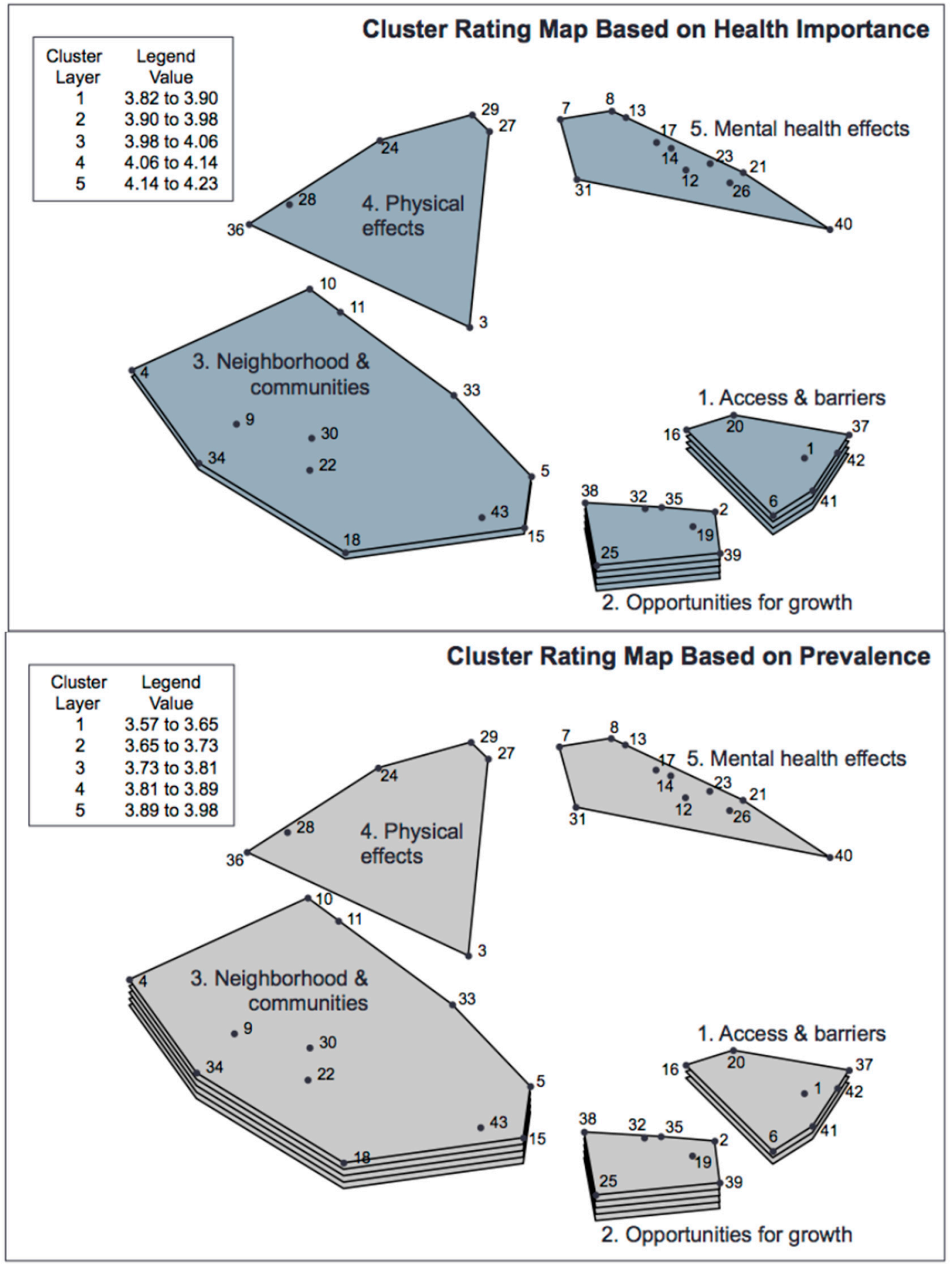

Figure 1. Cluster rating maps based on rating scores for health importance and prevalence.

\section{Discussion}

Using concept mapping methodology, the study identified various pathways describing the relation between housing discrimination and health. Five major themes emerged including, access and barriers, opportunities for growth, neighborhood and communities, physical effects of housing discrimination, and the mental effects. While two of these themes, physical and mental effects of housing discrimination, reflect the direct health effects of individual acts of housing discrimination, the other themes identified long-term health effects due to the resulting restricted life opportunities, 
including opportunities for growth, access and barriers, and the neighborhood and communities that individuals who have experience housing discrimination may be restricted to.

The statements found in the mental and physical effects of discrimination have been examined more closely when looking at other forms of discrimination including education and employment (Williams 1999). However, the long-term health effects due to the consequences of restrictions and barriers pathways have yet to be explored in direct relation to housing discrimination. From these findings, we can further study housing discrimination as a facilitator of segregation and displacement due to gentrification in this country, both related to negative health outcomes.

\subsection{Housing Discrimination, Residential Segregation, and Health}

Research has demonstrated the strong links between residential segregation and negative health outcomes (Acevedo-Garcia and Lochner 2003; Subramanian et al. 2005) including higher risk of mortality (Hart et al. 2011; Inagami et al. 2006), low birth weight (Bell et al. 2006), and cancer (Morello-Frosch and Jesdale 2006; Dai 2010). Although most of these findings have been done in the context of race-based segregation within the US, there is evidence from other countries including Spain, Italy and Helsinki, that show similar findings in the context of poverty- or socioeconomic-based segregation (Marí-Dell'Olmo et al. 2015; Marinacci et al. 2017). These studies ultimately show that disinvestment in these segregated neighborhoods, including limited opportunities for economic and social growth, can have negative health effects on residents for generations to come (Acevedo-Garcia and Lochner 2003). Some of the studies have traced segregation back to past policies that perpetuated inequalities like the racists policies of the Homeowners Loan Corporation (HOLC) of 1933 and the Federal Housing Administration in 1934 leading to much of the redlining that occurred across cities in the U.S. However, most have failed to recognize current practices that contribute continuously to segregation. Based on the findings of this study and others including the conceptual framework presented by Mehdipanah and colleagues (Mehdipanah et al. 2017a) that explores the systemic effects on the relation between homeownership, health and health inequities, we have a strong case to continue studying the pathways between housing discrimination, segregation, and health. Such studies can include examining the socio-demographic characteristics of neighborhoods in which race-based housing discrimination are more likely to occur to determine whether housing discrimination continues to perpetuate residential segregation in different cities.

\subsection{Housing Discrimination, Gentrification, and Health}

Our study did not ask for the connection between specific housing discrimination types (e.g., race, disability, familial status, and others) and health, and the resulting statements were applicable to all types. However, much of the existing health research on discrimination whether in housing, employment or education has largely focused on discrimination based on race (Williams 1999; Yang et al. 2016). Although this literature allows us to build upon, considerations for other types of housing discrimination in the context of gentrification should also be made including disability, source of income, familial status and age.

Although few studies have been able to show the link between gentrification, displacement, and health, there is existing evidence that adults over the age of 65 , people with disabilities, along with single mothers and people of color, are more vulnerable to displacement due to gentrification (Bacqué et al. 2011; Betancur 2011; Mehdipanah et al. 2017b). In particular, with increasing rents and the potential physical changes needed to facilitate mobility, seniors and people with disabilities, often on fixed-incomes, can face pressures from existing landlords to either adjust or move (Atkinson 2000; Biro 2007). When unable to cope, displacement can expose this population to further discrimination when looking for new homes (Danermark et al. 1996; Fan 2010) and worsen their mental and physical health due to the potential separation from existing social networks in the neighborhoods (Barrett 2013; Heller 1982). Therefore, future studies should explore whether pathways between types of discrimination and the location of discrimination coincide with neighborhood-level gentrification. 
From there, if possible, the pathways can be further studied to describe if the discrimination resulted in displacement and the health consequences of these events.

\subsection{Strengths and Limitations}

One of the strengths of this study was the participants themselves. Although as a first step in this exploratory process we aimed to capture professionals who worked with individuals who had experienced housing discrimination, through our demographic questionnaire we saw that most participants had themselves experienced some form of housing discrimination. This strengthened our findings by providing a mixture of both professional and individual perspectives. In addition to their own personal experiences, another strength of this study was their experience as frontline advocates. Through their daily interactions with individuals who have experienced housing discrimination, they are aware of both the short and long-term effects these incidents can have on people's lives.

One limitation of the study, and other traditional qualitative methodologies, is that concept mapping's goal is not to generalize findings to larger populations. Instead, our findings are meant to serve as an exploration of the topic and establish some of the potential pathways for future studies to test through other data collection and analysis methods.

\section{Conclusions}

This year (2018) marks the 50th anniversary of the Fair Housing Act, however, segregation continues to persist across the US because of the enduring discriminatory government policies in addition to illegal practices within the real estate industry (National Fair Housing Alliance 2018). More evidence is needed to solidify the pathways in which housing discrimination are negatively impacting individuals' lives and communities. The current study is part of a larger series of upcoming studies intended to examine both the direct and indirect health effects of housing discrimination. Based on findings from this study, more evidence is needed to better understand how neighborhood changes, and neighborhood characteristics are associated with housing discrimination incidents and outcomes, respectively, and the adverse health effects experienced by those who encounter housing discrimination. With this information, programs can target intervention and prevention efforts to neighborhoods at a higher risk of housing discrimination incidents, and work to protect the health of those at risk of housing discrimination. In addition, more evidence in this field will also provide the evidence that will help translate some of these health consequences of housing discrimination for application in actual cases. Traditionally damages awarded to individuals as compensation for loss or injury in fair housing cases have been low compared to damage awarded in comparable areas of tort law (Goode and Johnson 2003). Therefore, more evidence can support greater damages for individuals.

Supplementary Materials: The following are available online at http:/ /www.mdpi.com/2076-0760/7/10/194/s1, Supplementary 1: Clustered statements and ratings based on importance and prevalence of occurrence.

Author Contributions: R.M. and J.R. collected and analyzed the data. S.A. and S.F.B. provided guidance on participant recruitment and helped with the interpretation of the analyses. All authors contributed to the final manuscript.

Funding: This research received no funding.

Conflicts of Interest: The authors declare no conflicts of interest.

\section{References}

Acevedo-Garcia, Dolores, and Kimberly A. Lochner. 2003. Chapter 12: Residential Segregation and Health. In Ian Neighborhoods and Health. Edited by Ichiro Kawachi and Lisa F. Berkman. Oxford: Oxford University Press, pp. 265-87.

Atkinson, Rowland. 2000. The Hidden Costs of Gentrification: Displacement in Central London. Journal of Housing and the Built Environment 15: 307-26. [CrossRef] 
Bacqué, Marie-Hélène, Yankel Fijalkow, Lydie Launay, and Stéphanie Vermeersch. 2011. Social Mix Policies in Paris: Discourses, Policies and Social Effects. International Journal of Urban and Regional Research 35: 256-73. [CrossRef] [PubMed]

Barrett, Edith J. 2013. The Needs of Elders in Public Housing: Policy Considerations in the Era of Mixed-Income Redevelopment. Journal of Aging \& Social Policy 25: 218-33.

Bell, Janice F., Frederick J. Zimmerman, Gunnar R. Almgren, Jonathan D. Mayer, and Colleen E. Huebner. 2006. Birth Outcomes among Urban African-American Women: A Multilevel Analysis of the Role of Racial Residential Segregation. Social Science \& Medicine 63: 3030-45.

Betancur, John. 2011. Gentrification and Community Fabric in Chicago. Urban Studies 48: 383-406. [CrossRef] [PubMed]

Biro, Jessica. 2007. Gentrification: Deliberate Displacement, or Natural Social Movement? The Park Place Economist 15: 42-46. Available online: http://digitalcommons.iwu.edu/parkplace/vol15/iss1/12 (accessed on 5 June 2018).

Calmore, John O. 1997. Race/ism Lost and Found: The Fair Housing Act at Thirty. University of Miami Law Review 52: 1067-130.

Christensen, Peter, and Christopher Timmins. 2018. Sorting or Steering: Experimental Evidence on the Economic Effects of Housing Discrimination. NBER Working Paper No. 24826. Cambridge: NBER.

Chronopoulos, Themis. 2016. African Americans, Gentrification, and Neoliberal Urbanization: The Case of Fort Greene, Brooklyn. Journal of African American Studies 20: 294-322. [CrossRef]

Dai, Dajun. 2010. Black Residential Segregation, Disparities in Spatial Access to Health Care Facilities, and Late-Stage Breast Cancer Diagnosis in Metropolitan Detroit. Health E Place 16: 1038-52.

Danermark, Berth D., Mats E. Ekström, and Lennart L. Bodin. 1996. Effects of Residential Relocation on Mortality and Morbidity among Elderly People. European Journal of Public Health 6: 212-17. [CrossRef]

Erickson, Jim. 2016. Targeting Minority, Low-Income Neighborhoods for Hazardous Waste Sites. January 20. Available online: https:/ / phys.org/news/2016-01-minority-low-income-neighborhoods-hazardous-sites. html (accessed on 29 May 2018).

Fan, Yingling. 2010. Reexamining Contemporary Urbanism in the United States: Convenient Mix of the Old and New. Environment and Planning A 42: 2897. [CrossRef]

Goode, Victor, and Conrad Johnson. 2003. Emotional Harm in Housing Discrimination Cases: A New Look at a Lingering Problem. CUNY Academic Works. New York: CUNY School of Law.

Hart, Kevin D., Stephen J. Kunitz, Ralph. R. Sell, and Dana B. Mukamel. 2011. Metropolitan Governance, Residential Segregation, and Mortality among African Americans. American Journal of Public Health 88: 434-8. Available online: http:/ / ajph.aphapublications.org/ (accessed on 8 June 2018). [CrossRef]

Heller, Tamar. 1982. The Effects of Involuntary Residential Relocation: A Review. American Journal of Community Psychology 10: 471-92. [CrossRef] [PubMed]

Inagami, Sanae, Luisa N. Borrell, Mitchell D. Wong, Jing Fang, Martin F. Shapiro, and Steven M. Asch. 2006. Residential Segregation and Latino, Black and White Mortality in New York City. Journal of Urban Health 83: 406-20. [CrossRef] [PubMed]

Kane, Mary, and William M. K. Trochim. 2007. Concept Mapping for Planning and Evaluation. Thousand Oaks: Sage Publications.

Marí-Dell'Olmo, Marc, Mercè Gotsens, Laia Palència, Bo Burström, Diana Corman, Giuseppe Costa, Patrick Deboosere, Ėlia Díez, Felicitas Domínguez-Berjón, Dagmar Dzúrová, and et al. 2015. Socioeconomic Inequalities in Cause-Specific Mortality in 15 European Cities. Journal of Epidemiology Community Health 69: 432-41. [CrossRef] [PubMed]

Marinacci, Chiara, Moreno Demaria, Giulia Melis, Carme Borrell, Diana Corman, Marc Marí Dell'Olmo, Maica Rodriguez, and Giuseppe Costa. 2017. The Role of Contextual Socioeconomic Circumstances and Neighborhood Poverty Segregation on Mortality in 4 European Cities. International Journal of Health Services: Planning, Administration, Evaluation 47: 636-54. [CrossRef] [PubMed]

Massey, Douglas, and Nancy Denton. 1993. American Apartheid: Segregation and the Making of the Underclass. Cambridge: Harvard University Press. 
Mehdipanah, Roshanak, Amy J. Schulz, Barbara A. Israel, Graciela Mentz, Alexa Eisenberg, Carmen Stokes, and Zachary Rowe. 2017a. Neighborhood Context, Homeownership and Home Value: An Ecological Analysis of Implications for Health. International Journal of Environmental Research and Public Health 14: 1098. [CrossRef] [PubMed]

Mehdipanah, Roshanak, Giulia Marra, Giulia Melis, and Elena Gelormino. 2017b. Urban Renewal, Gentrification and Health Equity: A Realist Perspective. European Journal of Public Health. Available online: https:/ / doi. org/10.1093/eurpub/ckx202 (accessed on 25 January 2018). [CrossRef] [PubMed]

Michigan Civil Rights Commission. 2017. The Flint Water Crisis: Systemic Racism through the Lens of Flint. Michigan. Available online: http:/ / www.michigan.gov/documents/mdcr/VFlintCrisisRep-F-Edited3-1317_554317_7.pdf (accessed on 27 May 2018).

Morello-Frosch, Rachel, and Bill M. Jesdale. 2006. Separate and Unequal: Residential Segregation and Estimated Cancer Risks Associated with Ambient Air Toxics in U.S. Metropolitan Areas. Environmental Health Perspectives 114: 386-93. [CrossRef] [PubMed]

National Fair Housing Alliance. 2018. 2018 Fair Housing Trends Report. Available online: https:// nationalfairhousing.org/2018-fair-housing-trends-report/ (accessed on 28 September 2018).

Roscigno, Vincent J., Diana L. Karafin, and Griff Tester. 2009. The Complexities and Processes of Racial Housing Discrimination. Social Problems 56: 49-69. [CrossRef]

Sims, Revel J. 2016. More than Gentrification: Geographies of Capitalist Displacement in Los Angeles 1994-99. Urban Geography 37: 26-56. [CrossRef]

Subramanian, Subu V., Dolores Acevedo-Garcia, and Theresa L. Osypuk. 2005. Racial Residential Segregation and Geographic Heterogeneity in Black/white Disparity in Poor Self-Rated Health in the US: A Multilevel Statistical Analysis. Social Science \& Medicine 60: 1667-79.

Turner, Margery Austin, Robert Santos, Diane K. Levy, and Douglas A. Wissoker. 2016. Housing Discrimination against Racial and Ethnic Minorities 2012: Full Report. Urban Institute. June 4. Available online: https: / / www.urban.org/research/publication/housing-discrimination-against-racial-and-ethnicminorities-2012-full-report (accessed on 7 September 2018).

US Department of Justice. 2017. The Fair Housing Act. Available online: https://www.justice.gov/crt/fairhousing-act-1 (accessed on 21 May 2018).

Williams, David R. 1999. Race, Socioeconomic Status, and Health the Added Effects of Racism and Discrimination. Annals of the New York Academy of Sciences 896: 173-88. [CrossRef] [PubMed]

Williams, David R., and Pamela Braboy Jackson. 2005. Social Sources of Racial Disparities in Health. Health Affairs 24: 325-34. [CrossRef] [PubMed]

Yang, Tse-Chuan, Danhong Chen, and Kiwoong Park. 2016. Perceived Housing Discrimination and Self-Reported Health: How Do Neighborhood Features Matter? Annals of Behavioral Medicine 50: 789-801. [CrossRef] [PubMed]

Zhou, Yuhong, Amin Bemanian, and Kristen Beyer. 2017. Housing discrimination, residential racial segregation, and colorectal cancer survival in southeastern Wisconsin. Cancer Epidemiology Biomarkers E Prevention 26: 561-68.

(C) 2018 by the authors. Licensee MDPI, Basel, Switzerland. This article is an open access article distributed under the terms and conditions of the Creative Commons Attribution (CC BY) license (http:// creativecommons.org/licenses/by/4.0/). 